\title{
A Tribute to Alo Dutta (1964-2018)
}

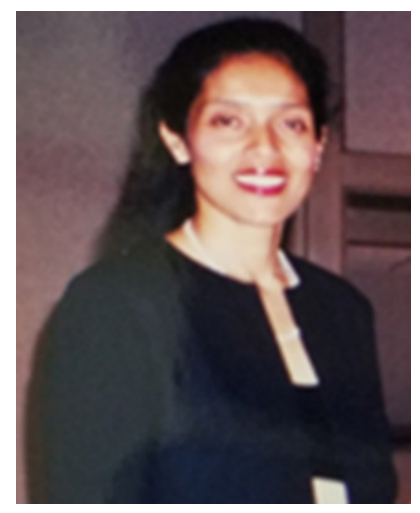

Dr. Alo Dutta.

Dr. Alo Dutta died on June 29, 2018 after battling with cancer. She has made significant academic and research contributions while at Southern University, Baton Rouge, Louisiana. She was a full professor in the Department of Rehabilitation and Disability Studies and served as Principal Investigator of the Vocational Rehabilitation Technical Assistance Center for Targeted Communities project.

Dr. Dutta was born in Calcutta (now Kolkata), India. She obtained her Bachelor of Science degree in physics, chemistry and mathematics from the University of Calcutta, India. She came to Southern to study professional accountancy and earned a master's degree. While at Southern, she learned about a new field of study in rehabilitation and earned a master's degree in rehabilitation counseling with Professor Madan Kundu as her major advisor. She received her Ph.D. in community health with a specialization in rehabilitation from the University of Illinois at Urbana-Champaign (2001) with Professor Chrisann Schiro-Geist.

Dr. Dutta has been on the faculty of rehabilitation counseling at Southern University since 2002, achieving the rank of Full Professor in 2016. Prior to joining the Southern University faculty, she held the position of Coordinator of Research at Howard University's
Rehabilitation Research and Training Center from 2001 to 2002 and as an Adjunct Assistant Professor at the University of the District of Columbia and Louisiana State University. Dr. Dutta was modest about her accomplishments. Her commitment to social justice, diversity and inclusion; kindness and intelligence will long be remembered by her students, colleagues, and friends.

Importantly, Dr. Dutta was an outstanding researcher, a prolific grant writer and a visionary leader in the field of vocational rehabilitation. She was the Principal Investigator/Project Director of 11 training, research, capacity building, and technical assistance grants; Co-Principal Investigator/Associate Project Director of nine (9) other grants, totaling \$31 million. These projects were funded by the Rehabilitation Services Administration, the National Institute on Disability, Independent Living and Rehabilitation Research, and the National Science Foundation. She was a highly valued consultant to the Federal government and to other universities. Her advice on capacity building, leadership, and long-range planning for inclusion of rehabilitation educators and researchers from racial and ethnic minority backgrounds was highly sought after. Most importantly, Dr. Dutta was a valuable colleague and a faithful friend to many in the rehabilitation community. She was quiet in nature, smart, creative, industrious, productive, and reliable.

Dr. Dutta served on the Editorial Board and as a Guest Reviewer of 10 journals and Editor of 2 newsletters. She has published 48 refereed journal articles and 5 book chapters, and made over 80 presentations at state, regional, national and international conferences. She was the recipient of 14 awards and recognitions, including Outstanding Graduate Student Award; Researcher of the Year Award; Young Investigator Award; the National Council on Rehabilitation Education (NCRE) New Career in Rehabilitation Education; and National Rehabilitation Association Job Placement Research Award 
(2006 and 2012). She was very active in local, regional and national rehabilitation professional organizations, including the National Rehabilitation Counseling Association, the National Council on Rehabilitation Education, National Association of Multicultural Rehabilitation Concerns, and the Vocational Evaluation and Work Adjustment Association.

Dr. Dutta was a selfless person. She donated her eyes to the Eye Bank and her body to the Louisiana State University School of Medicine in New Orleans for education and research. Without a doubt, the field of rehabilitation has lost a gentle giant, and she will always have a special place in the hearts of her students and colleagues, as she has touched many lives.

The Dr. Alo Dutta Memorial Scholarship Fund is established in her memory to continue her legacy of scholarly research and publications in advancing the cause of people with disabilities and the field of rehabilitation counseling by recognizing an outstanding doctoral dissertation and to provide travel funds for presentation at the annual spring conference of the National Council on Rehabilitation Education (NCRE). Please make your tax-deductible contributions payable to the DR. ALO DUTTA MEMORIAL SCHOLARSHIP FUND and mail to Dr. Madan Kundu, 231 Blanks Hall, Department of Rehabilitation and Disability Studies, Southern University, Baton Rouge, LA 70813, USA.

Dr. Madan Kundu, Chair and Professor, Southern University

Dr. Fong Chan, Professor Emeritus, University of Wisconsin-Madison 